\title{
Editorial
}

\section{Acknowledgment to Reviewers of Recent Progress in Materials in 2021}

\author{
Recent Progress in Materials Editorial Office
}

LIDSEN Publishing Inc., 2000 Auburn Drive, One Chagrin Highlands, Suite 200, Beachwood, OH, USA; E-Mail: rpm@lidsen.com

* Correspondence: Recent Progress in Materials Editorial Office; E-Mail: rpm@lidsen.com

Recent Progress in Materials

2022, volume 4, issue 1

doi:10.21926/rpm.2201001
Received: January 05, 2022

Accepted: January 05, 2022

Published: January 06, 2022

\begin{abstract}
The editors of Recent Progress in Materials would like to express their sincere gratitude to the following reviewers for assessing manuscripts in 2021. We greatly appreciate the contribution of expert reviewers, which is crucial to the journal's editorial process. We aim to recognize reviewer contributions through several mechanisms, of which the annual publication of reviewer names is one. Reviewers receive a voucher entitling them to a discount on their next LIDSEN publication and can download a certificate of recognition directly from our submission system. Additionally, reviewers can sign up to the service Publons (https://publons.com) to receive recognition. Of course, in these initiatives we are careful not to compromise reviewer confidentiality. Many reviewers see their work as a voluntary and often unseen part of their role as researchers. We are grateful to the time reviewers donate to our journals and the contribution they make.
\end{abstract}

The editors of Recent Progress in Materials would like to express their sincere gratitude to the following reviewers for assessing manuscripts in 2021.

We greatly appreciate the contribution of expert reviewers, which is crucial to the journal's editorial process. We aim to recognize reviewer contributions through several mechanisms, of which the annual publication of reviewer names is one. Reviewers receive a voucher entitling them to a discount on their next LIDSEN publication and can download a certificate of recognition

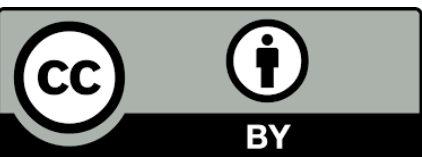

(C) 2022 by the author. This is an open access article distributed under the conditions of the Creative Commons by Attribution License, which permits unrestricted use, distribution, and reproduction in any medium or format, provided the original work is correctly cited. 
directly from our submission system. Additionally, reviewers can sign up to the service Publons (https://publons.com) to receive recognition. Of course, in these initiatives we are careful not to compromise reviewer confidentiality. Many reviewers see their work as a voluntary and often unseen part of their role as researchers. We are grateful to the time reviewers donate to our journals and the contribution they make.

If you are interested in becoming a reviewer for Recent Progress in Materials, see the link at the bottom of the webpage https://www.lidsen.com/joinus.

The following reviewed for Recent Progress in Materials in 2021:

\begin{tabular}{|c|c|c|}
\hline Al-Khateeb, Susan Nadeem & He, Hong & Ren, Jie \\
\hline Alvarez, José Ignacio & Henriksson, Marielle & Ren, Miao \\
\hline Amiandamhen, Stephen O. & Heuchel, M. & Rokaya, Dinesh \\
\hline An, Xingye & Hosseinkhani, Hossein & Sadeghian, Pedram \\
\hline Ashish, Deepankar Kumar & Jabbarzadeh, Ahmad & Şahin, Yuşa \\
\hline Aydin, Ertug & Juszyńska-Gałązka, Ewa & Sheng, Liyuan \\
\hline Babayevska, Nataliya & Kadkhodaei, M. & Shi, Jinyan \\
\hline Bahl, Shashi & Karimipour, Arash & Shi, Yaning \\
\hline Bashiri Rezaie, Ali & Landi, Daniele & Shukla, Ravi K. \\
\hline Bordère, Sylvie & Lecompte, Thibaut & Singh, Deepti \\
\hline Bourdot, Alexandra & Li, Leo Gu & Souissi, Maaouia \\
\hline Budzinski, Maik & Li, Peng & Sun, Fangda \\
\hline Chen, Hongbing & Liu, Xujie & Švajlenka, Jozef \\
\hline Chen, Liang & Livney, Yoav D. & Tefa, Luca \\
\hline Correa, Diego Rafael Nespequ & Marceau, Sandrine & $\begin{array}{l}\text { Tugova, Ekaterina } \\
\text { Alekseevna }\end{array}$ \\
\hline Dai, Yunqian & Merlo, Aloir A. & Tyagi, Pawan \\
\hline de Brito, Jorge & Milazzo, Maria Francesca & Villapún, Victor M. \\
\hline de Souza, Luiz K.C. & Mirhashemi, Amirhossein & Wang, Yuanfeng \\
\hline Dierking, Ingo & Mrukiewicz, Mateusz & Welshons, Wade V. \\
\hline Ding, Junjun & Mustapha, Kabiru & Westphal, Erik \\
\hline Dong, Hua & Naser, Mohannad Zeyad & Wu, Dazhi \\
\hline Faria, Paulina & Neffe, Axel T. & Xiao, Xinli \\
\hline
\end{tabular}


Recent Progress in Materials 2022; 4(1), doi:10.21926/rpm.2201001

\begin{tabular}{|l|l|l|}
\hline Ferreira, Jose & Pan, Jian & Yamaguchi, Satoshi \\
\hline Gai, Wen-mei & Papageorgiou, Asterios & Yang, Congcong \\
\hline Ge, Shengbo & Peric, Tamara & Yoshihara, Hiroshi \\
\hline Geng, Yue & Pokorný, Jaroslav & Yu, Hongfa \\
\hline Ghosh, A. & Qin, Ling L. & Zelekew, Osman Ahmed \\
\hline Glé, Philippe & Qu, Zhiguo & Zhang, Yan \\
\hline Godat, Ahmed & Ralegaonkar, Rahul & Zhang, Yue \\
\hline
\end{tabular}

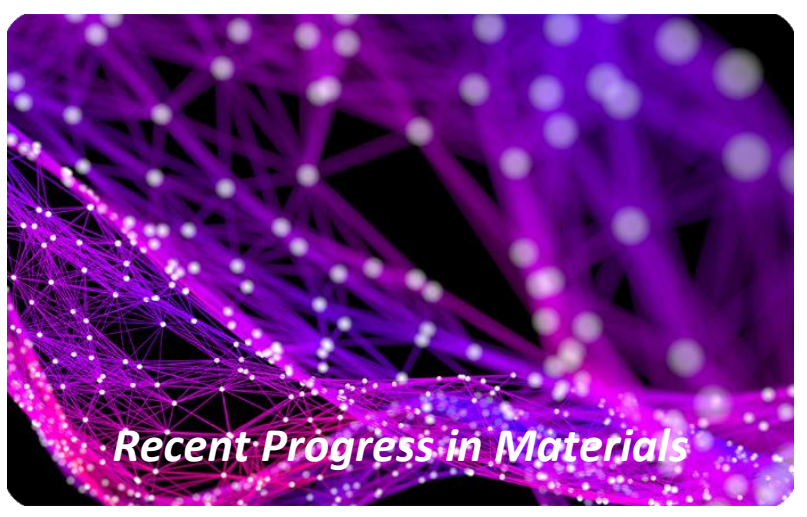

Enjoy Recent Progress in Materials by:

1. Submitting a manuscript

2. Joining in volunteer reviewer bank

3. Joining Editorial Board

4. Guest editing a special issue

For more details, please visit:

http://www.lidsen.com/journals/rpm 